\title{
Development and Verification of an Interspecific Hybridization Protocol for Asclepias
}

\author{
Mary Lewis, Matthew Chappell, Paul A. Thomas, and \\ Rebekah C. Maynard \\ Department of Horticulture, University of Georgia, 1111 Miller Plant \\ Science Building, Athens, GA 30602

\section{Ockert Greyvenstein \\ Ball Horticultural Company, 400 Obispo Street, Guadalupe, CA 93434}

Additional index words. Asclepiadoideae, butterfly weed, gynostemium, monarch butterfly, native plant, pollinia

\begin{abstract}
Milkweed (Asclepias sp.) is an important pollinator genus across North America and is a host plant for many butterfly species, notably the monarch butterfly (Danaus plexippus). Commercial production of Asclepias is limited to a few species, because most species lack commercial traits, with minimal branching habit, excessive height, and minimal color variation. This study used a commercially viable Asclepias species, butterfly weed (Asclepias tuberosa L.), as a maternal parent and trialed three different pollination methods in an attempt to create interspecific hybrids. Pollination methods included a traditional method, a pollen-solution-based method, and a novel inverted pollinia method. The inverted pollinia method increased pollination success rates 4-fold among intraspecific crosses of $A$. tuberosa. When pollination methods were optimized, $A$. tuberosa was used as the maternal parent, and one-way crosses were made to seven other Asclepias species using the inverted pollinia method. Of the seven species used as pollen donors, four developed hybrid seed successfully: green milkweed (Asclepias hirtella Woodson), purple milkweed (Asclepias purpurascens L.), showy milkweed (Asclepias speciosa Torr.), and common milkweed (Asclepias syriaca L.). As germination methods vary significantly among Asclepias species, three methods of germination were trialed on seed developed via interspecific hybridizations: direct seeded, cold-moist stratification, and embryo rescue. Of the three methods, cold-moist stratification was superior to direct seeding and embryo rescue. This research is the first documented case of a controlled interspecific hybridization event among these species.
\end{abstract}

Asclepias L. is a member of the Apocynaceae (milkweed family) that is comprised of 106 species native to North America (Woodson, 1954; Wyatt and Broyles, 1994). Many species are important nectar sources for indigenous butterfly species (Luna and Dumroese, 2013). In addition, adult butterflies use many species for oviposition sites, with larvae using foliage as a food source (Brower, 1969; Hutchings, 1923). Several Asclepias species are known for attractive floral structures (including fragrant blooms) and exceptional performance

Received for publication 9 Feb. 2021. Accepted for publication 20 Apr. 2021.

Published online 8 June 2021.

We appreciate the support of Ball Horticultural Company, Foothills Compost Inc., Pan American Seed, Harrell's Fertilizers LLC, and the UGA Research Foundation. We also credit the idea of this project to the late Paul Thomas, who always thought this concept to be possible when others did not. We also appreciate internal manuscript reviews provided by Julie Campbell and Cain Hickey.

M.C. is the corresponding author. E-mail: hortprod@uga.edu.

This is an open access article distributed under the CC BY-NC-ND license (https://creativecommons. org/licenses/by-nc-nd/4.0/) in landscape environments despite minimal fertilizer and irrigation inputs. However, some species have traits that make them difficult to produce commercially. Excessive height, particularly in high-fertility soils indicative of commercial production environments, limits commercial viability. Poor branching, aversion to moist soil conditions, and poor germination rates have also dissuaded many commercial producers from adopting Asclepias species into production. Outside of seed-produced varieties developed for the cut-flower industry, little genetic improvement has taken place in the genus, with minimal clonally produced cultivars available to ornamental producers.

A major reason for the lack of breeding and selection progress is that Asclepias boasts one of the most complex reproductive structures known in the plant kingdom (Wyatt, 1976). Much like the Orchidaceae family, pollen is transmitted via pollinia, or sac-like structures containing pollen. Pollinia are part of a "lock and key" pollination method (Stebbins, 1970) whereby successful pollination requires removing pollinia from the corpusculum of the pollen parent, usually via a pollinator's rake and comb (on legs), drying for a short period (typically during flight), rotating $90^{\circ}$, and then inserting into the stigmatic slit of the maternal parent to facilitate fertilization. Pollinia and stigmatic slit size vary depending on the species, and these differences are purported to limit successful, naturally occurring interspecific hybridization via pollinator activity (Wyatt and Broyles, 1994). Asclepias is also unusual in that they have two independent ovaries and, if pollinia are inserted perfectly, all subsequent seed will share a single pollen parent (genotype) (Wyatt and Broyles, 1994). When removed from the corpusculum, pollen is viable within the pollinia packet for about 4 d. However, the fertilization rate declines by $50 \%$ after the first $24 \mathrm{~h}$ (Kephart, 1981).

The complex floral structure of Asclepias encourages outcrossing and carries an S-locus gene that fosters either gametophytic or sporophytic self-incompatibility (SI) (Lipow and Wyatt, 2000). The gene is late acting in the ovary and hinders endosperm maturation (Lipow and Wyatt, 2000). This postzygotic SI is highly polymorphic and, as such, can be overcome if favorable genetic recombination occurs (Lipow and Wyatt, 2000). Despite knowledge of the mechanisms of SI, overcoming all aspects of it has not been investigated thoroughly in the genus. Levels of SI can vary from species to species (even within species), and additional factors can impact success of self-fertilization. For example, even when successful pollinations are made, it remains unknown as to why the seed pods abort if less than half the seeds (embryos) are fertilized (Bookman, 1984; Kahn and Morse, 1991).

Given the major physiological and ecological barriers presented, hybridization of Asclepias (both intra- and interspecific) has had relatively little success in published reports. Recent genetic diversity work has shown that a lack of success in interspecific hybridizations may be influenced by high levels of genetic diversity among Asclepias species, as well as potentially differing chromosome numbers (Weitemier et al., 2015). Despite potential genetic barriers that would inhibit the creation of interspecific hybrids within Asclepias, successful interspecific hybrids could yield segregating populations with greater phenotypic variability to draw upon when selecting $F_{1}$ individuals for potential commercial release (Wyatt and Hunt, 1991).

Among Asclepias species, there is also wide variability in geographic range and specific habitat requirements. Therefore, many Asclepias species have evolved in relative physiographical isolation. This could have contributed to greater genetic diversity among species. Habitat (e.g., cultural) variability among species, while limiting natural interspecific hybridization, suggests that controlled crosses could result in progeny with wider environmental tolerance resulting from hybrid vigor (Ellstrand and Schierenbeck, 2000). Hybridization is also promising in that the amount of diversity in this genus should be extensive enough to identify novel phenotypes that could be commercially viable. These commercially viable phenotypes may express hybrid vigor and/or intermediate phenotypes that yield improved pest/pathogen tolerance, improved 
plant form, novel flower color, improved growth and flowering rates, and/or sterility.

High genetic diversity and habitat variability among Asclepias species have contributed to relatively few documented interspecific hybridizations, both naturally occurring and in controlled environments. Studies investigating natural interspecific hybridizations have suggested that success was a function of habitat overlap on the margins of the species ranges, and may be more common than previously thought (Broyles, 2002; Klips and Culley, 2004; Wyatt and Broyles, 1992; Wyatt and Hunt, 1991). Some species have also been hybridized successfully under controlled conditions (Kephart and Heiser, 1980). Successful crosses under controlled conditions have been between $A$. speciosa $\times A$. syriaca (Stevens, 1945), poke milkweed (A. exaltata L.) $\times A$. syriaca (Broyles, 2002; Wyatt and Hunt, 1991), A. exaltata $\times$ whorled milkweed $(A$. quadrifolia Jacq.), and $A$. purpurascens $\times A$. syriaca (Kephart et al., 1988). All of these successful crosses occurred from species in the same phylogenetic clade based upon a recent genetic diversity study (Weitemier et al., 2015).

Genome size, ploidy, and chromosome number are unknown for many Asclepias species. This creates uncertainty when selecting species to use in controlled hybridizations. Despite a lack of comprehensive genetic information available for all Asclepias species, recent amplified fragment length polymorphism diversity estimates (Weitemier et al., 2015) provide a starting point whereby species sharing clades (indicating greater genetic similarity) could be tested for interspecific compatibility. Based on previously documented successful interspecific hybridization efforts (Kephart and Heiser, 1980; Kephart et al., 1988; Stevens, 1945; Wyatt and Hunt, 1991), it would be logical to use species from the same clade as a starting point for breeding efforts.

Variability in seed dormancy also presents a challenge when developing interspecific Asclepias hybrids, with many species having no defined stratification or seed treatment protocol. A. tuberosa seedling dormancy is classified as primary dormancy and is overcome with $30 \mathrm{~d}$ of cold-moist stratification, removal of the seedcoat, or gibberellic acid treatment
(Evetts and Burnside, 1972). However, A. syriaca and $A$. purpurascens require cold stratification for 1 year after maturity before their germination rate reaches 50\% (Baskin and Baskin, 1977; Groh, 1943). Asclepias species also have a juvenile period that ends after one season of vegetative growth following seedling germination (Shannon and Wyatt, 1986). During the second year of growth, flower production is initiated, and plants will produce flowers perennially from that point forward (Shannon and Wyatt, 1986). Published accounts indicate that all Asclepias species are facultative long-day plants that can be forced to flower by exposing plants to 15 -h days, night interruption of $5 \mathrm{~min}$ every hour, and $25^{\circ} \mathrm{C}$ day $/ 14^{\circ} \mathrm{C}$ night temperatures (Albrecht and Lehmann, 1991).

The objectives of our project were 3-fold. The first was to determine an optimal pollination protocol for $A$. tuberosa. The second was to use the developed pollination protocol to attempt interspecific hybridizations using $A$. tuberosa as the model maternal parent and seven other species as pollen parents. These seven species were chosen based on their relative relatedness (and unrelatedness) to $A$. tuberosa genetically, diversity in growing conditions, flower color, fragrance, height, branching, and current prevalence in the commercial market. The third objective was to determine whether a seed treatment protocol could be identified to maximize germination of hybrid seed.

\section{Materials and Methods}

Parent production. Seven species were initially grown from seed to serve as pollen parents, with $A$. tuberosa serving as the maternal parent (Table 1, Fig. 1). Upon receiving seed from their differing locations (Table 1), all seed lots were divided into their respective species, wrapped in a moist paper towel, then wrapped in aluminum foil and placed in $0.004-\mathrm{m}^{3}$ (1-gal) Ziploc bags. Seeds were then cold-moist stratified in a refrigerator held at 3 to $4{ }^{\circ} \mathrm{C}$ for $30 \mathrm{~d}$. Upon removal from stratification, seeds were germinated in Oct. 2018 at the University of Georgia Athens campus, College Station Greenhouse
Complex (lat. $33.9480^{\circ} \mathrm{N}$, long. $83.3773^{\circ} \mathrm{W}$ ) in 804 inserts (T.O. Plastics, Minneapolis, $\mathrm{MN}$ ) containing $100 \%$ perlite (Carolina Perlite Co. Inc., Gold Hill, NC) with a topdressing of vermiculite (TX401, BWI, Greer, SC) to a $0.635-\mathrm{cm}$ depth. Supplemental light was provided by light-emitting diode (LED) arrays (Fluence Spyder with PhysioSpec; Fluence Technologies Inc., Austin, TX), providing a photosynthetic photon flux $(P P F)$ density of $250 \mu \mathrm{mol} \cdot \mathrm{m}^{-2} \cdot \mathrm{s}^{-1}$ and $14-\mathrm{h}$ daylength. Seedlings were placed on a mist bench, with a misting cycle applying municipal water (pH 6.2 and alkalinity of $11 \mathrm{ppm}$ ) at $6 \mathrm{~s}$ every $10 \mathrm{~m}$. Greenhouse temperatures were maintained at $25^{\circ} \mathrm{C}$ (day) and $18^{\circ} \mathrm{C}$ (night). Upon germination and expansion of the first set of true leaves, seedlings were transplanted into 804 inserts (T.O. Plastics) held by 1020 greenhouse trays (T.O. Plastics) filled with $80 \%$ milled peat (Sungro Peat Moss Grower Grade Orange; Sun Gro, Agawam, MA) and $20 \%$ perlite (Carolina Perlite Co. Inc.). Once established, seedlings were transplanted into $0.004-\mathrm{m}^{3}$ (1-gal) containers (Classic 400; Nursery Supply, Agawam, MA) containing an $80 \%$ bark (3/8-inch particle size) and $20 \%$ milled peat (Foothills Compost, Gainesville, GA). Throughout the seedling germination, establishment, and transplanting stages, seedlings were irrigated with municipal water and fertilized twice a week with Peter's 20N-4.4P-16.6K liquid-soluble fertilizer (Scotts Co., Marysville, OH) at 100 ppm. For all species, 130 plants in $0.004-\mathrm{m}^{3}$ containers were produced. When plants were established in containers, the plants to be used in interspecific breeding objectives were placed into cold storage, with environmental conditions consisting of $96 \%$ relative humidity and a temperature of 3 to $4{ }^{\circ} \mathrm{C}$. Chilling hour requirements to induce flowering of the various species were unknown, so 15 plants of each species were removed from cold storage at 2week intervals beginning at 8 weeks and ending at 34 weeks. When plants were removed from cold storage, they were placed in a greenhouse with temperatures at $25^{\circ} \mathrm{C}$ (day) and $18^{\circ} \mathrm{C}$ (night). Fluence Spyder LED arrays (Fluence Spyder with PhysioSpec; Fluence Technologies Inc.) with the PhysioSpec spectrum were used

Table 1. Asclepias species used with selected phenotypic traits of interest to commercial producers.

\begin{tabular}{|c|c|c|c|c|c|c|c|}
\hline Species & $\mathrm{Ht}(\mathrm{cm})$ & Soil $^{\mathrm{z}}$ & Flower color & Bloom $^{\mathrm{y}}$ & Fragrant & Branching & Seed source ${ }^{x}$ \\
\hline A. tuberosa ${ }^{\mathrm{W}}$ & $30-100$ & Dry & Yellow/orange & Medium & No & Yes & WCGa \\
\hline A. curassavica & $60-91$ & Medium & Yellow/red & Long & No & None & Ball \\
\hline A. fascicularis & $30-90$ & Dry & White/pink & Long & Yes & Some & USDA \\
\hline A. hirtella & $90-120$ & Wet & Green & Medium & No & None & $\mathrm{EF}, \mathrm{PMN}$ \\
\hline A. incarnata & $120-150$ & Wet & Pink/mauve & Long & Yes & Some & EF, PMN, USDA \\
\hline A. purpurascens & $60-90$ & Dry & Purple/pink & Long & Yes & None & $\mathrm{EF}, \mathrm{WC}$ \\
\hline A. speciosa & $60-180$ & Dry & White/pink & Long & Yes & None & PMN, USDA \\
\hline A. syriaca & $120-180$ & Dry & Pink & Short & Yes & None & PMN, USDA \\
\hline
\end{tabular}

\footnotetext{
${ }^{\mathrm{z}}$ Soil represents an arbitrary soil moisture preference based on textbooks.
}

${ }^{\mathrm{y}}$ Bloom length (Bloom) is not given in numerical length because this information was not available for all species. In general, flowering continues for 2 to 3 months; flowering longevity and flower viability are not documented in all species.

${ }^{\mathrm{x}} \mathrm{WCGa}=$ wild collected from Oglethorpe County, GA; Ball = Ball Horticulture Co., Chicago, IL; USDA = U.S. Department of Agriculture, Columbus, OH, and Parlier, CA, germplasm centers; EF = Everwilde Farms, Fallbrook, CA; PMN = Prairie Moon Nursery, Winona, MN; WC = wild collected in Idiantown and Lebanon County, PA.

${ }^{\mathrm{w}}$ A. tuberosa represents both the maternal parent of all crosses and the species used to develop the optimal pollination method. 


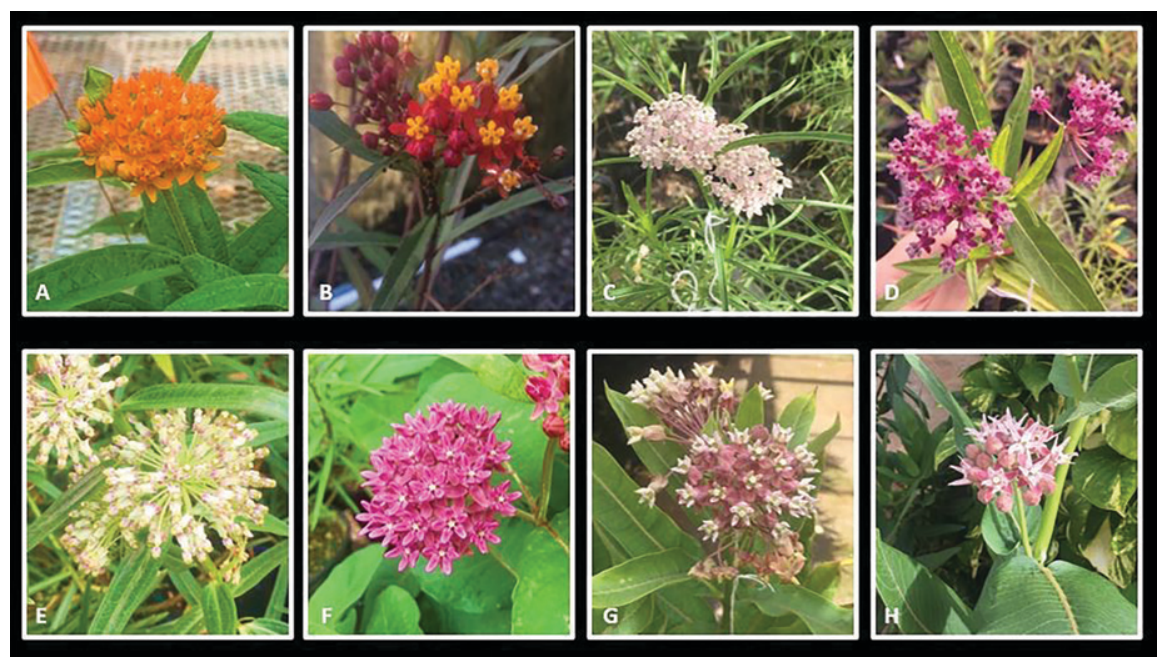

Fig. 1. Species used to develop interspecific hybrid populations: (A) Asclepias tuberosa (maternal parent), (B) A. curassavica, (C) A. fascicularis, (D) A. incarnata, (E) A. hirtella, (F) A. purpurascens, (G) A. syriaca, and (H) A. speciosa.

as supplemental lighting, maintaining a $P P F$ of $250 \mu \mathrm{mol} \cdot \mathrm{m}^{-2} \cdot \mathrm{s}^{-1}$ and a $14-\mathrm{h}$ daylength. Asclepias species are long-day plants and typically initiate flowering under 14-h days (starting 18 May in Athens, GA). New growth was pinched back to the fourth node at week 5 after dormancy break. Pinching was performed to promote greater branching and thus greater number of flowers produced.

Hybridization protocol. All interspecific crosses attempted were one-way crosses using A. tuberosa as the female parent. The species used as pollen donors were $A$. curassavica L., A. fascicularis Decne., $A$. hirtella, A. incarnata L., A. purpurascens, $A$. speciosa, and $A$. syriaca. Based on previous work (Wyatt, 1981) and preliminary floral observations (data not shown), the inner 9 to 10 flowers of $A$. tuberosa open concurrently, with outer florets opening sporadically over 7 to $10 \mathrm{~d}$. To reduce unintentional selfing, outer florets were removed, leaving only the inner 9 to 10 florets. Preliminary
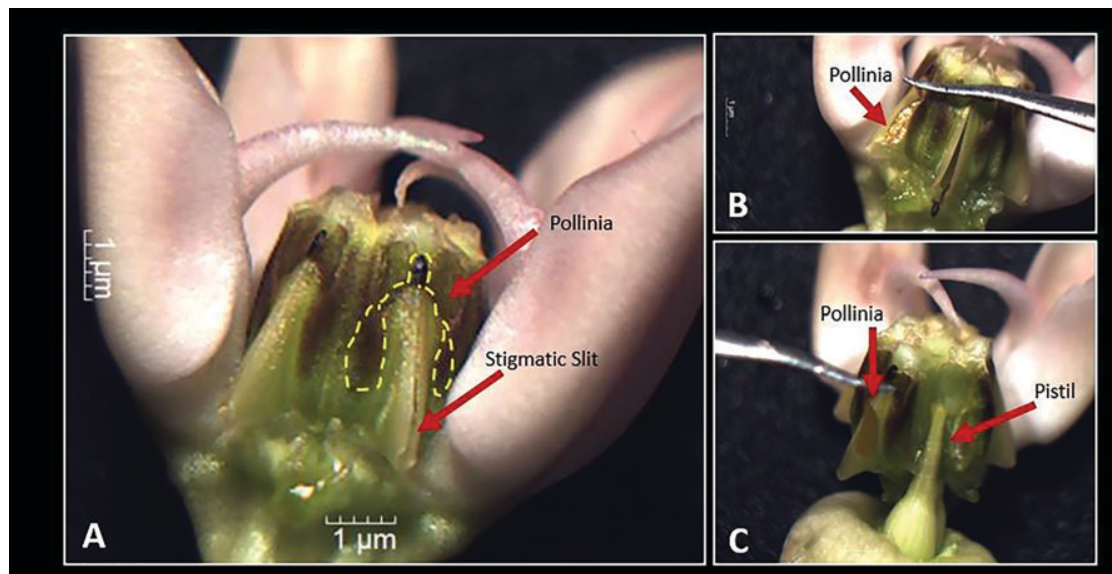

Fig. 2. (A) Depicted using the largest pollen parent $A$. speciosa, the traditional pollination method involves removing pollinia packets from inside the gynostegium. (B) Individual pollinium are rotated $90^{\circ}$ from how they sit in the gynostegium and are inserted parallel into the stigmatic slit to initiate pollination and fertilization. $(\mathbf{C})$ Where the pollinia rests after inserted in relation to the pistil located in the gynostegium. stigmatic slit), rotated $90^{\circ}$ (inverted to pollinia edge), and inserted into the stigmatic chamber of the A. tuberosa maternal genotype parallel to the stigmatic slit (Fig. 2). One to two pollinium (two pollinium making one pollinia) from the same pollen parent were inserted into one stigmatic chamber of each floret of the maternal parent, and the same pollen donor parent was used for the entire floral structure (9-10 florets). About 550 pollinations were completed using this method. The second method was a solution-based pollination method. Pollen inside pollinia were determined to germinate optimally when suspended in a $30 \%$ sucrose solution (Wyatt and Shannon, 1986). Using $1 \mathrm{~mL}$ of a $30 \%$ sucrose solution, five different numbers of pollinia (p) $(100 \mathrm{p}, 200 \mathrm{p}$, $250 \mathrm{p}, 350 \mathrm{p}$, and $450 \mathrm{p}$ ) were combined and crushed using a mortar and pestle (FB970J; Fisher Scientific, Lenexa, KS). After suspending pollen in $1 \mathrm{~mL}$ sucrose solution, a $1-\mathrm{mL}$ hypodermic needle (Terumo Medical Corp., Elkton, MD) was used to insert the pollen solution through the stigmatic slit and into the gynostegium (the main structure of the flower made from the fused filaments and stigma) (Fig. 3B) until excess solution exuded from the stigmatic slit. For each pollinia concentration, between 95 and 900 crosses were made. The third pollination method was a variation of the first described method (Wyatt, 1976). Rather than inserting pollinia parallel to the stigmatic slit, pollinia were inserted perpendicular to the stigmatic slit, which is best described as inserting a key into a lock (Fig. 4) as opposed to sliding a credit card in a reader. In each case, the convex end of the pollinia pointed downward, to be closer to the stigma after insertion into the stigmatic slit. Ideally, this would increase the chance of successful pollinations as a result of closer proximity and orientation of the pollinia and germination pore to the internal pistil (Galil and Zeroni, 1969). About 400 pollinations were conducted initially using this method, and after data comparison between the other pollination techniques (Fig. 3), 7000 additional crosses among additional pollen parent species (A. curassavica, A. fascicularis, $A$. hirtella, $A$. incarnata, $A$. purpurascens, $A$. speciosa, and $A$. syriaca) and A. tuberosa (maternal parent) were carried out. Reciprocal crosses were not attempted because of space limitations. After pollination, flowers were tagged with the date the cross was made, paternal and maternal parent species, and the number of florets pollinated. Flowers were bagged and the resulting seed pods were allowed to mature until dehiscence initiated or seed pods were brown.

Germination. Upon harvest of mature seed pods from individual crosses, seeds were removed from the seed pod and the length of the seed pod was measured. Seeds from each individual pod were then counted and divided equally and randomly into three groups. Seeds from the three groups were used as three treatment methods to determine the optimal stratification method. One-third of the seeds were immediately (upon harvest) sown in $100 \%$ perlite with a top dressing of vermiculite at a 0.635 -cm depth [direct-seeded (DS)]. Another 


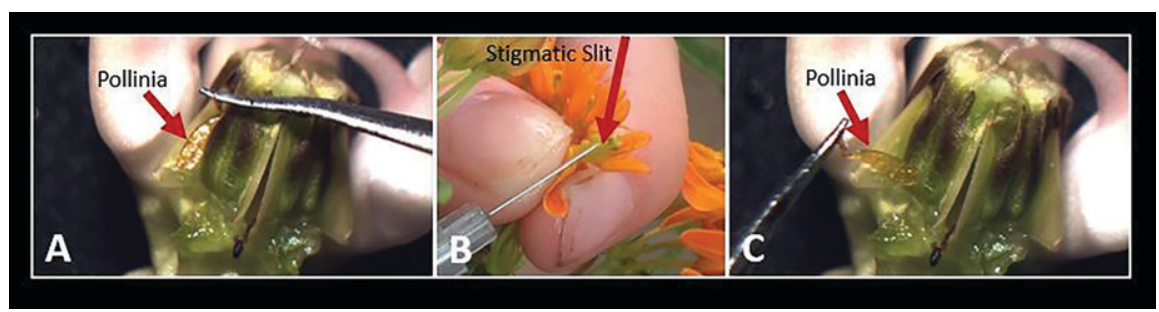

Fig. 3. Three methods of pollination were trialed: traditional, solution based, and inverted. (A) The traditional method is when individual pollinium is rotated $90^{\circ}$ and inserted parallel into the stigmatic slit to initiate pollination and fertilization. (B) Solution-based pollination uses differing numbers of pollinia removed from paternal flowers, crushed in $1 \mathrm{~mL}$ of a $30 \%$ sucrose solution, and dispensed inside the stigmatic slits until solution exuded from the stigmatic slit. (C) The inverted pollination method is when individual pollinium is rotated $90^{\circ}$ and inserted perpendicular to the stigmatic slit to initiate pollination and fertilization.

third of seeds were placed immediately into cold-moist stratification for $30 \mathrm{~d}$ at 3 to $4{ }^{\circ} \mathrm{C}$ in washed builder's sand media (stratified). After stratification, seeds were sown by filling 1020 greenhouse trays with $100 \%$ perlite, placing seed on the surface of the perlite, and covering with $0.635 \mathrm{~cm}$ of vermiculite. Germination for DS and stratified seed was initiated by placing flats on a mist bench using municipal water applied at a rate of $6 \mathrm{~s}$ of mist every $10 \mathrm{~m}$. After seedlings germinated and the cotyledons expanded, seedlings were transferred to 804 inserts (32-cell trays) held by 1020 greenhouse trays (with holes) filled with $80 \%$ composted bark, $10 \%$ milled peat, and $10 \%$ perlite mix, and irrigated using municipal water as needed. Thirty days after transplanting seedlings into flats, flats were placed in cold storage for 12 weeks at $96 \%$ relative humidity and a temperature of 3 to $4{ }^{\circ} \mathrm{C}$. The final third of seeds underwent embryo rescue (ER) as described by Lewis et al. (2020). Resulting ER plantlets were allowed to mature in culture for $60 \mathrm{~d}$ before removing from culture and hardening off in the greenhouse. Plantlets arising from ER were rinsed in municipal tap water and transferred to 804 inserts (32-cell trays) held by 1020 greenhouse trays (with holes) filled with
$80 \%$ composted bark, $10 \%$ milled peat, and $10 \%$ perlite mix before being placed in a humidity chamber receiving $6 \mathrm{~s}$ of mist every $10 \mathrm{~s}$. Plants were exposed incrementally to lower humidity levels over 3 weeks and then were moved to mist benches with the same environmental conditions as DS and stratified seeds before being transferred to cold storage.

On removal from cold storage, all hybrid seedlings (DS, stratified, and ER) were placed in a greenhouse with temperatures at $24^{\circ} \mathrm{C}$ (daytime) and $20^{\circ} \mathrm{C}$ (nighttime). Fluence Spyder LED arrays with the PgysioSpec spectrum were used as supplemental lighting, maintaining a $P P F$ of $250 \mu \mathrm{mol} \cdot \mathrm{m}^{-2} \cdot \mathrm{s}^{-1}$ and a 15-h daylength. When seedlings broke dormancy, plants were transferred to $0.004-\mathrm{m}^{3}$ containers filled with $80 \%$ bark (particle size, $0.98 \mathrm{~cm}$ ) and $20 \%$ milled peat mix, and were top-dressed with Harrell's 20N-6.6P-16K controlled-release fertilizer. Twice weekly, additional fertility was provided via a Peter's $20 \mathrm{~N}-4.4 \mathrm{P}-16.6 \mathrm{~K}$ liquid-soluble fertilizer at $100 \mathrm{ppm}$. Otherwise, all plants were handwatered as needed using municipal water.

Data collection and analysis. Preliminary data on parents were collected for individual parental genotypes and included time to first flower (in days after dormancy break). To

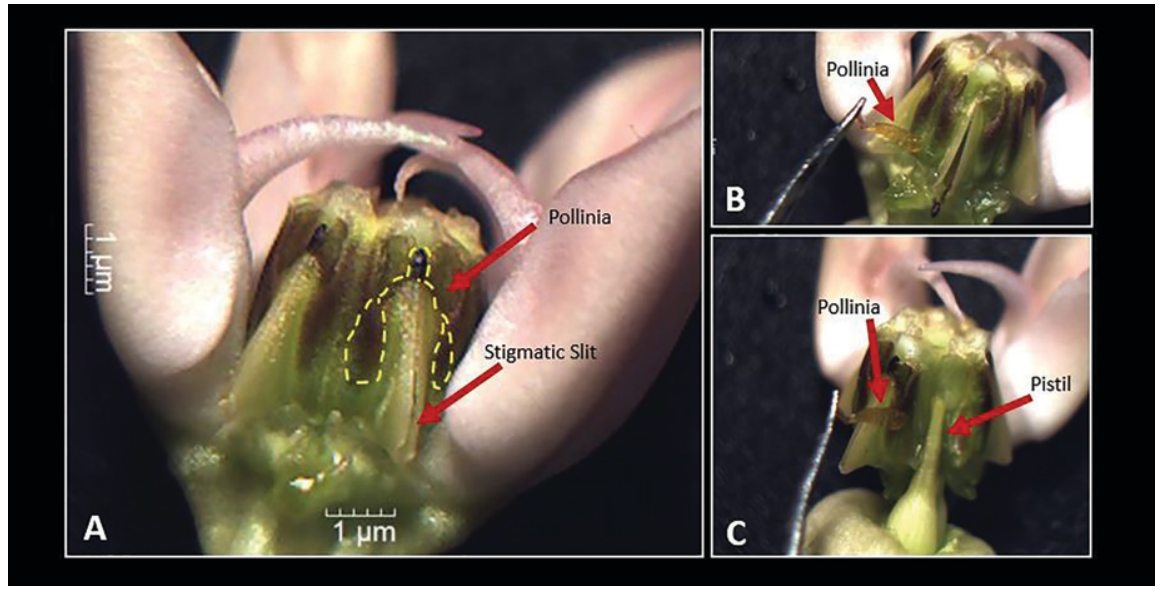

Fig. 4. (A) The inverted pollination method involves removing pollinia packets from inside the gynostegium. (B) The individual pollinium is rotated $90^{\circ}$ from how it sits in the gynostegium and is inserted perpendicular to the stigmatic slit to initiate pollination and fertilization. (C) Shown is where the pollinia rest after insertion in relation to the pistil in the gynostegium. determine the optimal pollination methodology among $A$. tuberosa genotypes, the total number of crosses were recorded using each pollination technique, and the number of pods resulting from each method was recorded. After obtaining preliminary hybridization technique results, the optimal pollination method (inverted pollination) was used for interspecific hybridizations using $A$. tuberosa (maternal parent) and the seven paternal species. Data collected from these hybridizations included the total number of florets hybridized per parental combination, number of successful pollinations as measured by seed pod formation (by parent combination), and days from pollination to seed maturity for each seed pod. At seed harvest, data collected included seed pod length for each successful hybrid seed pod and the number of seeds in each pod. Upon seeding (using DS or stratification techniques), the germination percentage for all seed by cross (individual seed pods) and within species combinations was recorded.

All data collection occurred in a single controlled-environment greenhouse structure with uniform environmental conditions. Temperature, light, and production inputs (e.g., soil and fertility) were regulated to minimize environmental effects on the production of $F_{1}$ phenotypes. Parental plants and $F_{1}$ genotypes were arranged in a completely randomized design within the greenhouse. Statistical analysis was performed using JMP (version 13.0; SAS Institute, Cary, NC). Data were analyzed to determine normality and homogeneity, with one-way analysis of variance and separation of treatment means using Tukey's honestly significant difference test to analyze differences among pollination methods, percentage of pod set depending on pollen donors, average length of time until pod harvest, DS germination percentage, stratified seed germination percentage, and ER germination percentage. Only data showing significant differences $(\alpha=0.05, P \leq 0.05)$ among treatments are reported.

\section{Results and Discussion}

Optimizing pollination methods. The extremely low rates of pollination success using traditional pollination methods (Wyatt, 1976) served as a stimulus for experimenting with differing pollination methods. During preliminary trials that involved attempts to make successful $A$. tuberosa intraspecific hybrids among genotypes of $A$. tuberosa in this study, $\approx 100$ crosses were needed to obtain one seed pod using traditional pollination methods. In this preliminary work, each cross took $1 \mathrm{~min}$, or $100 \mathrm{~m}$ for each successful hybrid seed pod. Alternative pollination methods were sought out as a result of the ineffectiveness and inefficiency of traditional methods. In pistachio (Pistacia vera L.), kiwi (Actinidia chinensis Planch.), and Japanese pear (Pyrus pyrifolia L.), increased levels of pollination success were observed when pollen grains were suspended in sucrose and/or agar solution and sprayed on flowers (Sakamoto et al., 2009; Yano et al., 2006; Zeraatkar et al., 2013). 
Table 2. Results from three pollination methods tested to determine seed set optimization for future hybrid crosses in intraspecific $A$. tuberosa crosses: traditional pollinations, solution, and inverted pollinia pollination. Solution pollination occurred at four different concentrations of pollinia (p) to one $\mathrm{mL}$ of $30 \%$ sucrose solution.

\begin{tabular}{lccc}
\hline Method & Crosses (n) & Pods (n) & Percent success \\
\hline Traditional & 570 & 13 & $2.28 \pm 0.84 \mathrm{~b}^{\mathrm{Z}}$ \\
Solution 200p: $1 \mathrm{~mL}$ & 185 & 0 & $0 \mathrm{~b}$ \\
Solution 250p: $1 \mathrm{~mL}$ & 113 & 0 & $0 \mathrm{~b}$ \\
Solution 350p: $1 \mathrm{~mL}$ & 915 & 0 & $0 \mathrm{~b}$ \\
Solution 450p: $1 \mathrm{~mL}$ & 95 & 0 & $0 \mathrm{~b}$ \\
Inverted & 401 & 47 & $11.72 \pm 1.00 \mathrm{a}$ \\
\hline
\end{tabular}

${ }^{\mathrm{Z}}$ Letters by means represent a significant difference based upon Tukey's honestly significant difference test at $P \leq 0.0001$.

Wyatt and Shannon (1986) indicated germination of pollinia was optimized when suspended in a $30 \%$ sucrose solution. Based on these results, we hypothesized that suspending pollen in a sucrose solution and injecting the solution through the stigmatic slit and into the gynostegium may increase seed pod set. However, when compared with a concurrent trial of traditional pollination, the solution-based method resulted in no pod formation (Table 2). The traditional pollination method (Wyatt, 1976) had a final pollination success rate of $2.28 \pm 1.00 \%$ (Table 2). During the process of making traditional pollinations, researchers noticed that pollinia could be inserted perpendicular to the stigmatic slit (at the bottom of the slit), and doing so could enable direct contact of the pollinia with the stigmatic surface, located in the stigmatic chamber. This technique was refined and is termed the "inverted pollination method," which resulted in an $11.72 \pm 1.14 \%$ success rate (Table 2 ) when attempting intraspecific hybridizations. With a 4-fold increase in pod set compared with traditional methods, the inverted pollination method was applied to all interspecific hybridizations attempted in this study. We postulated that the inverted pollination method yielded superior results because the pollinia are placed in direct contact with the stigmatic surface, when compared with the traditional pollination method (Figs. 3C and 4C). The solution-based pollination method was likely unsuccessful as a result of inconsistent solution deposition inside the gynostegium. Controlling the release of solution and not rupturing the gynostegium with the pressure difference, while making the pollinations, was challenging.

Interspecific hybridization. Seven Asclepias species were used as pollen parents, with A. tuberosa serving as the maternal parent for all hybridizations (Table 1, Fig. 1). About 1000 inverted pollination attempts were made per parent combination between Mar. and Oct. 2018, resulting in 253 hybrid pods. Four paternal species produced successful interspecific hybridizations with $A$. tuberosa (maternal parent): A. hirtella, A. purpurascens, A. speciosa, and $A$. syriaca (Table 3 ). Although no paternal species resulted in a pod set rate greater than $A$. tuberosa (inverted), A. speciosa had a success rate of $8.58 \pm 0.70 \%$, similar to intraspecific $A$. tuberosa using the same pollination method (Table 3). A. syriaca had the lowest success rate $(3.71 \pm 0.63 \%)$, which was similar to included (and documented) as the control. 0.001 . for all hybrid crosses was $A$. tuberosa. ence (HSD) test at $P \leq 0.001$. similar genetically than the species that failed to form hybrid seed.

Very little information exists on seed pod maturity [measured in days after pollination (DAP)] of interspecific hybrid seed pods vs. hybrid parents in ornamental crops. It should be noted that seed (embryo and endosperm) often matures earlier than seed pods, and thus drawing a correlation between seed maturity and the date the seed pod matures could lead to confounding principles. Because seed pod maturity (measured in DAP) differs among Asclepias species in native environments, the length of time needed for pods to reach maturity based on their pollen parent was recorded in our study. A. tuberosa intraspecific pollinated data were used as the control because these could serve as a test of cytoplasmic or nuclear inheritance of seed pod maturity. Overall, Asclepias pod maturity was achieved in 93.38 to 126.64 DAP, with differences noted in pod maturity depending on the pollen parent. $A$. speciosa (pollen parent) had the quickest pod maturity of $93.38 \pm 2.78 \mathrm{~d}$ (Table 4). A. tuberosa (control) had a maturation time of $110.32 \pm 3.87 \mathrm{~d}$, similar to $A$. syriaca pods $(114.14 \pm 3.84 \mathrm{~d})$ (Table 4$). A$. purpurascens and $A$. hirtella hybrid pods took the longest to mature, taking $124.64 \pm$ $3.55 \mathrm{~d}$ for $A$. purpurascens hybrid pods to mature and $126.64 \pm 3.52 \mathrm{~d}$ for A. hirtella hybrid pods to mature. This indicates that seed pod maturity differs based on the paternal parent, and therefore is not a maternally inherited (cytoplasmic) trait.

Little published work exists on seed pod growth parameters among populations of interspecific hybrids. For this reason, seed pod length and seeds per pod of hybrid crosses were compared with a control of intraspecific $A$. tuberosa genotypes. The average pod length of intraspecific pollinated $A$.

Table 3. Successful seed pod formation for four Asclepias species hybridized with A. tuberosa and their corresponding success rates.The traditional pollination method used on $A$. tuberosa is

\begin{tabular}{lccr}
\hline Pollen donor (father) & Crosses $(\mathrm{n})$ & Pods $(\mathrm{n})$ & Percent success \\
\hline A. tuberosa (control) & 570 & 13 & $2.28 \pm 0.96 \mathrm{~b}^{\mathrm{y}}$ \\
A. tuberosa (inverted) & 401 & 47 & $11.72 \pm 1.14 \mathrm{a}$ \\
A. hirtella & 1,159 & 58 & $5.00 \pm 0.67 \mathrm{~b}$ \\
A. purpurascens & 1,142 & 56 & $4.90 \pm 0.68 \mathrm{~b}$ \\
A. speciosa & 1,071 & 91 & $8.50 \pm 0.70 \mathrm{a}$ \\
A. syriaca & 1,294 & 48 & $3.71 \pm 0.64 \mathrm{~b}$
\end{tabular}

${ }^{\mathrm{z}}$ All crosses apart from $A$. tuberosa (control) were made using the inverted pollination method.

${ }^{\mathrm{y}}$ Letters by means represent groupings based upon Tukey's honestly significant difference test at $P \leq$

Table 4. A comparison of the average length of time to harvest (in days after pollination) among different hybrid crosses. A. tuberosa intraspecific hybrid means served as the control. Maternal parent

\begin{tabular}{lccc}
\hline Pollen donor & Days to pod harvest $(\mathrm{avg})^{\mathrm{z}}$ & ${\text { Avg pod length }(\mathrm{cm})^{\mathrm{y}}}$ & ${\text { Seeds per pod }(\operatorname{avg})^{\mathrm{z}}}^{\text {A. tuberosa }}$ \\
\hline A. hirtella & $110.32 \pm 3.87 \mathrm{~b}$ & $10.69 \pm 0.28 \mathrm{ab}$ & $50.67 \pm 3.13 \mathrm{ab}$ \\
A. purpurascens & $126.64 \pm 3.52 \mathrm{a}$ & $11.12 \pm 0.26 \mathrm{a}$ & $61.33 \pm 2.94 \mathrm{a}$ \\
A. speciosa & $124.64 \pm 3.55 \mathrm{a}$ & $10.15 \pm 0.27 \mathrm{ab}$ & $32.93 \pm 2.99 \mathrm{c}$ \\
A. syriaca & $93.38 \pm 2.78 \mathrm{c}$ & $9.99 \pm 0.21 \mathrm{~b}$ & $49.60 \pm 2.34 \mathrm{~b}$ \\
\hline
\end{tabular}

${ }^{\mathrm{z} L e t t e r s ~ b y ~ m e a n s ~ r e p r e s e n t ~ s i m i l a r i t y ~ w i t h i n ~ c o l u m n s ~ b a s e d ~ u p o n ~ T u k e y ' s ~ h o n e s t l y ~ s i g n i f i c a n t ~ d i f f e r-~}$

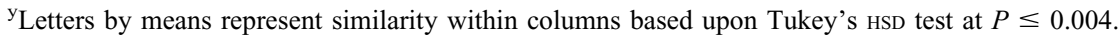




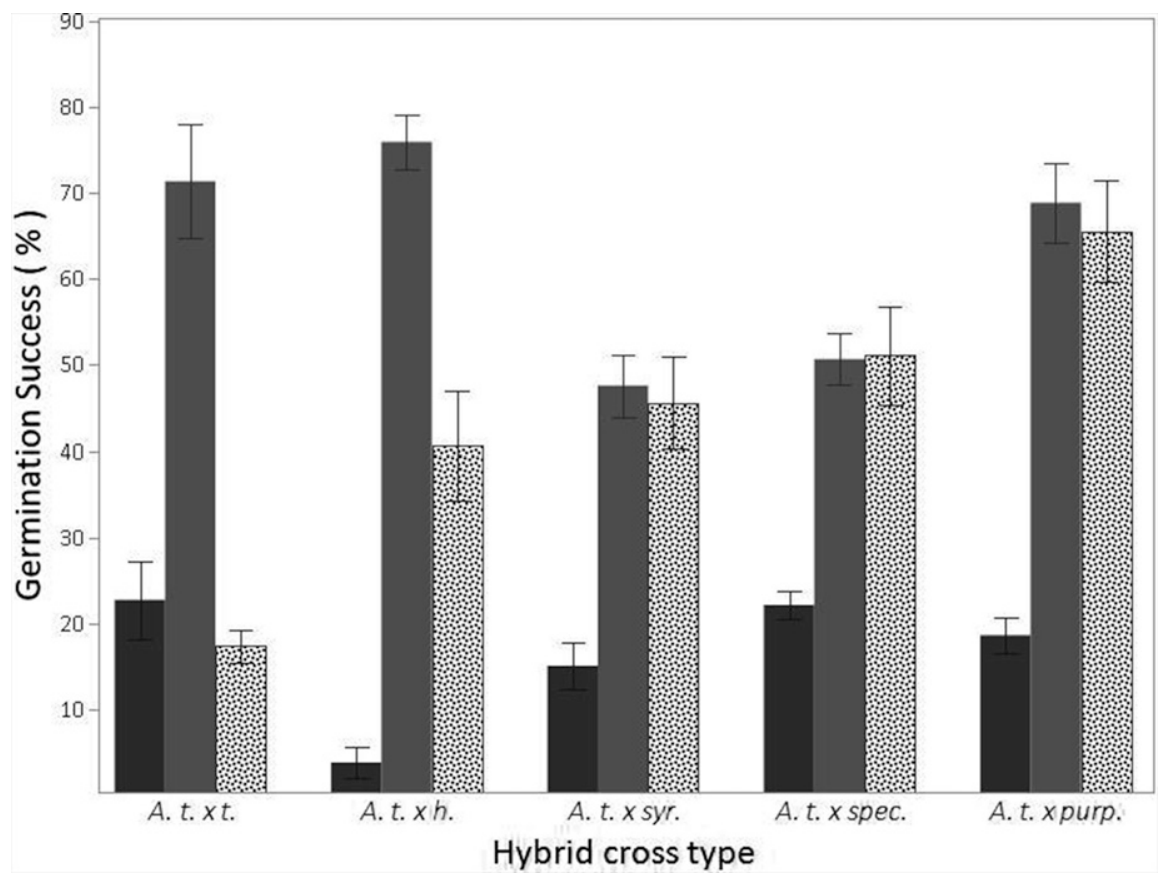

Fig. 5. Comparison of three methods of germination based on successful pod set among Asclepias hybrid populations with different pollen parents: direct seeded (dark gray), stratified (gray), and embryo rescue (speckled). Bars represent means, with error bars displaying 1 sE from the mean at $P<0.001$. Each error bar is constructed using one SE from the mean. Hybrids compared were tuberosa (A. t. $\times$ t. intraspecific crosses), A. tuberosa by: A. hirtella $(A . t . \times$ h. $)$, A. syriaca (A.t. $\times$ syr.), A. speciosa (A.t. $\times$ spec.), and A. purpurascens (A.t. $\times$ purp.).

tuberosa genotypes was $10.69 \pm 0.28 \mathrm{~cm}$ and did not differ from other hybrid populations having varied paternal parents (Table 4). Only $A$. hirtella hybrids $(11.12 \pm 0.26 \mathrm{~cm})$ produced longer pods when compared with A. speciosa hybrids $(9.99 \pm 0.21 \mathrm{~cm})$ and $A$. syriaca hybrids $(9.92 \pm 0.29 \mathrm{~cm})$ (Table 4$)$. $A$. tuberosa had a pod length ranging from 8.4 to $15.5 \mathrm{~cm} ; A$. hirtella, from 7.0 to 11.8 $\mathrm{cm}$; A. purpurascens, from 9.0 to $15.0 \mathrm{~cm}$; and $A$. syriaca, from 6.5 to $13.6 \mathrm{~cm}$ (Betz and Lamp, 1992; Wilbur, 1976). The number of seeds per pod did not vary among intraspecific A. tuberosa and A. hirtella, A. speciosa, and $A$. syriaca hybrid populations. A. purpurascens hybrids produced the fewest seed per pod $(32.92 \pm 2.99)$ (Table 4). In a study of Asclepias species, Betz and Lamp (1992) determined that $A$. tuberosa, on average, produced $73.8 \pm 14.7$ seeds, which is greater than the seed counts observed in our study. $A$. hirtella was documented to produce $51.2 \pm$ 7.2 seeds per pod in the wild (Betz and Lamp, 1992), which was similar to hybrid $A$. hirtella results observed in our study. However, wild seed production in A. purpurascens $(180.7 \pm 31.5)$ and $A$. syriaca $(244.3 \pm$ 31.2) (Betz and Lamp, 1992) was much greater compared with observed seed set of hybrids in our study (Table 4).

Germination methods. Germination methods for Asclepias species vary depending on their native range. A. curassavica does not require a germination treatment to break seed dormancy, whereas A. syriaca requires an extended seed dormancy period (of a year or more) combined with cold stratification before a germination rate of $50 \%$ or more can be achieved (Baskin and Baskin, 1977; Groh, 1943). A. fascicularis requires 4 to 6 weeks of stratification to break dormancy, and $A$. speciosa requires, on average, 2 to 4 weeks of stratification (Kaye et al., 2018). As hybrid parents varied in germination requirements, the two most common germination methods of DS and stratification were used to determine the optimal germination method. ER, as described previously by Lewis et al. (2020), was also compared with DS and stratification in an attempt to ensure some hybrids were recovered. Within the DStreated hybrid populations, only $A$. hirtella hybrids germinated at a lower rate $(3.82 \pm$ $2.2 \%)$ than the control, intraspecific $A$. tuberosa $(22.7 \pm 3.18 \%)$ (Fig. 5). Within the stratified seed treatment, $A$. hirtella hybrids and $A$. purpurascens hybrids had similar germination rates $(75.94 \pm 3.7 \%$ and $68.88 \pm 4.1 \%$, respectively) compared with $A$. tuberosa $(71.37 \pm 5.6 \%)$, while $A$. speciosa hybrid seed and $A$. syriaca hybrid seed had lower germination rates $(50.71 \pm$ $2.99 \%$ and $47.60 \pm 4.17 \%$, respectively) (Fig. 5). In the ER treatment, only $A$. purpurascens $(65.53 \pm 5.12 \%)$ had a greater germination rate than $A$. tuberosa $(17.35 \pm$ $13.19 \%$ ) (Fig. 5). Overall, the DS germination method was the least successful, followed by ER, with the most effective germination method being stratification (Fig. 5). As all species used in successful hybridizations have native ranges from zones 3 to 8 , with large concentrations of the population in northern climates having a distinct (dormant) winter season, a necessity for stratification is understandable.

\section{Conclusion}

This study documents the first controlled interspecific hybridizations between $A$. tuberosa and $A$. hirtella, A. purpurascens, A. speciosa, and $A$. syriaca. Previous articles predominantly reported naturally occurring hybrids or intraspecific hybrids. Development of an effective pollination method increased pollination success from $2 \%$ to $11 \%$, and increased the efficiency and effectiveness of crosses. Of seven species selected to be pollen donors, 7000 crosses were made, which yielded more than 250 viable hybrid pods that matured within 93.38 to 126.64 d. A. speciosa hybrid pods matured the quickest, whereas $A$. purpurascens and $A$. hirtella hybrid pods took the longest. Of the 15,000 seeds collected from all hybridizations, $\approx 5500$ genotypes germinated successfully. Three different germination techniques were assessed: DS, stratification, and ER. It was determined that cold-moist stratification is necessary to achieve maximum germination. Although ER was the second-most effective method of germination, cost could be a barrier to its use in commercial plant breeding efforts. The goal of these studies was to determine whether interspecific hybridizations were possible and, if so, the most efficient method to produce viable germplasm for breeding purposes. It was found that interspecific hybridization is possible, and that progeny could germinate successfully using the stratification techniques identified as part of our study. These findings provide a starting point for future breeding efforts of Asclepias and showcase the potential of introducing novel or improved cultivars of Asclepias to the commercial market.

\section{Literature Cited}

Albrecht, M.L. and J.T. Lehmann. 1991. Daylength, cold storage, and plant-production method influence growth and flowering of Asclepias tuberosa. HortScience 26:120-121, doi: https://doi.org/ 10.21273/HORTSCI.26.2.120.

Baskin, J.M. and C.C. Baskin. 1977. Germination of common milkweed (Asclepias syriaca L.) seeds. Bull. Torrey Bot. Club 104:167-170.

Betz, R.F. and H.F. Lamp. 1992. Flower, pod, and seed production in eighteen species of milkweeds (Asclepias). In: Proc. of the Twelfth N. Amer. Prairie Conf. Cedar Falls: Univ. of Iowa. $25-30$.

Bookman, S.S. 1984. Evidence for selective fruit production in Asclepias. Evolution 38:72-86.

Brower, L.P. 1969. Ecological chemistry. Sci. Amer. 220:22-28.

Broyles, S.B. 2002. Hybrid bridges to gene flow: A case study in milkweeds (Asclepias). Evolution 56:1943-1953, doi: https://doi.org/10.1111/j.00 14-3820.2002.tb00120.x.

Chromosome Counts Database. 2019. CCDB database. 10 Nov. 2019. <http://ccdb.tau.ac.il/>.

Darlington, C.D. and A.P. Wylie. 1956. Chromosome atlas of flowering plants, p. 231. Macmillan Company, New York, NY.

Ellstrand, N.C. and K.A. Schierenbeck. 2000 Hybridization as a stimulus for the evolution of invasiveness in plants. Proc. Natl. Acad. Sci. USA 97:7043-7050, doi: https://doi.org/10.1073/ pnas.97.13.7043.

Evetts, L.L. and O.C. Burnside. 1972. Germination and seedling development of common milkweed 
and other species. Weed Sci. 20:371-378, doi: https://doi.org/10.1017/S004317450003589X.

Fishbein, M., D. Chuba, C. Ellison, R.J. MasonGamer, and S.P. Lynch. 2011. Phylogenetic relationships of Asclepias (Apocynaceae) inferred from non-coding chloroplast DNA sequences. Syst. Bot. 36:1008-1023, doi: https://doi.org/ $10.1600 / 036364411$ X605010.

Galil, J. and M. Zeroni. 1969. On the organization of the pollinium in Asclepias curassavica. Bot. Gaz. 130:1-4.

Groh, H. 1943. Notes on common milkweed. Sci. Agr. 23:625-632.

Heiser, C.B., Jr. and T.W. Whitaker. 1948. Chromosome number, polyploidy, and growth habit in California weeds. Amer. J. Bot. 35:179-186.

Hutchings, C.B. 1923. A note of the monarch or milkweed butterfly with special reference to its migratory habits. Can. Field Nat. 37:150.

Kahn, A.P. and D.H. Morse. 1991. Pollinium germination and putative ovule penetration in selfand cross-pollinated common milkweed Asclepias syriaca. Amer. Midl. Nat. 126:61-67, doi: https://doi.org/10.2307/2426149.

Kaye, T.N., I.J. Sandlin, and M.A. Bahm. 2018. Seed dormancy and germination vary within and among species of milkweeds. AoB Plants 10:18, doi: https://doi.org/10.1093/aobpla/ply018.

Kephart, S.R. 1981. Breeding systems in Asclepias incarnata L., A. syriaca L., and A. verticillata L. Amer. J. Bot. 68:226-232, doi: https://doi. org/10.2307/2442854.

Kephart, S.R. and C.B. Heiser. 1980. Reproductive isolation in Asclepias: Lock and key hypothesis reconsidered. Soc. Study Evol. 34:738-746, doi: https://doi.org/10.1111/j.1558-5646.1980. tb04013.x.

Kephart, S.R., R. Wyatt, and D. Parrella. 1988. Hybridization in North American Asclepias: I. morphological evidence. Syst. Bot. 13:456-473, doi: https://doi.org/10.2307/2419307.
Klips, R.A. and T. Culley. 2004. Natural hybridization between prairie milkweeds, Asclepias sullivantii and Asclepias syriaca: Morphological, isozyme, and hand-pollination evidence. Intl. J. Plant Sci. 165:1027-1037, doi: https://doi.org/ $10.1086 / 423875$.

Lewis, M.E., M. Chappell, D. Zhang, and R. Maynard. 2020. Development of an embryo rescue protocol for butterfly weed. HortTechnology 30:31-37, doi: https://doi.org/10.21273/ HORTTECH04440-19.

Lipow, S.R. and R. Wyatt. 2000. Single gene control of postzygotic self-incompatibility in poke milkweed, Asclepias exaltata L. Genetics 154: 893-907.

Luna, T. and R. Dumroese. 2013. Monarchs (Danaus plexippus) and milkweeds (Asclepias species): The current situation and methods for propagating milkweeds. Native Plants J. 14:5-15, doi: https://doi.org/10.3368/npj.14.1.5.

Sakamoto, D., H. Hayama, A. Ito, Y. Kashimura, T. Moriguchi, and Y. Nakamura. 2009. Spray pollination as a labor-saving pollination system in Japanese pear [Pyrus pyrifolia (Burm. f.) Nakai)]: Development of the suspension medium. Scientia Hort. 119:280-285, doi: https:// doi.org/10.1016/j.scienta.2008.08.009.

Shannon, T.R. and R. Wyatt. 1986. Reproductive biology of Asclepias exaltata. Amer. J. Bot. 73:1-20, doi: https://doi.org/10.1002/j.15372197.1986.tb09675.x.

Stebbins, G.L. 1970. Adaptive radiation of reproductive characteristics in angiosperms: I. Pollination mechanisms. Annu. Rev. Ecol. Syst. 1:307-321.

Stevens, O.A. 1945. Asclepias syriaca and A. speciosa, distribution and mass collections in North Dakota. Amer. Midl. Nat. 34:368-374, doi: https://doi.org/10.2307/2421124.

Weitemier, K., S.C. Straub, M. Fishbein, and A. Linston. 2015. Intragenomic polymorphisms among high-copy loci: A genus-wide study of nuclear ribosomal DNA in Asclepias (Apocynaceae).
PeerJ 3:718, doi: https://doi.org/10.7717/peerj. 718.

Wilbur, H.M. 1976. Life history evolution in seven milkweeds of the genus Asclepias. J. Ecol. 64:223-240, doi: https://doi.org/10.2307/2258693.

Woodson, R.E. 1954. The North American species of Asclepias L. Ann. Miss. Bot. Garden 41:1-211.

Wyatt, R. 1976. Pollination and fruit-set in Asclepias: A reappraisal. Amer. J. Bot. 63:845-851, doi: https://doi.org/10.2307/2442044.

Wyatt, R. 1981. The reproductive biology of Asclepias tuberosa. New Phytol. 88:375-385, doi: https://doi.org/10.1111/j.1469-8137.1980. tb04453.x.

Wyatt, R. and S.B. Broyles. 1992. Hybridization in North American Asclepias: III. Isozyme evidence. Syst. Bot. 17:640-648, doi: https://doi. org/10.2307/2419732.

Wyatt, R. and S.B. Broyles. 1994. Ecology and evolution of reproduction in milkweeds. Annu. Rev. Ecol. Syst. 25:423-441, doi: https://doi org/10.1146/annurev.es.25.110194.002231.

Wyatt, R. and D.M. Hunt. 1991. Hybridization in North American Asclepias: II. Flavonoid evidence. Syst. Bot. 16:132-142, doi: https://doi. org/10.2307/2418978.

Wyatt, R. and T.R. Shannon. 1986. Pollen germinability of Asclepias exaltata: Effects of flower age, drying time, and pollen source. Amer. Soc. Plant Taxonomy 11:322-325, doi: https:// doi.org/10.2307/2419122.

Yano, T., N. Miyata, and H. Matsumoto. 2006. The use of liquid pollen extender thickened with polysaccharides for artificial pollination of kiwifruit. Intl. Symp. Kiwifruit 753:415-424, doi: https:// doi.org/10.17660/ActaHortic.2007.753.53.

Zeraatkar, H., H.R. Karimi, M.H. Shamshiri, and A. Tajabadipur. 2013. Preliminary evaluation of artificial pollination in pistachio using pollen suspension spray. Plant Knowledge J. 2:94, doi: https:// doi.org/10.3316/informit.765743142376202. 